\title{
Assessment of pesticide residue levels in common fruits consumed in Lagos State, Nigeria
}

\author{
Koleayo Omoyajowo', Kelechi Njoku², Sunday Amiolemen ${ }^{1}$, John Ogidan ${ }^{1}$, Olapeju Adenekan ${ }^{1}$, Kayode \\ Olaniyan ${ }^{3}$, Julie Akande ${ }^{3}$, Ifeoluwa Idowu ${ }^{3}$
}

${ }^{1}$ Department of Science Policy and Innovation Studies, National Centre for Technology Management, Victoria Island, Lagos, Nigeria

${ }^{2}$ Department of Cell Biology and Genetics (Environmental Biology Laboratory) University of Lagos, Akoka, Nigeria

${ }^{3}$ Nigeria Natural Medicine Development Agency, Victoria Island, Lagos, Nigeria

\section{Correspondence}

Koleayo Omoyajowo,

Department of Science Policy and Innovation Studies,

National Centre for Technology Management,

9. Kofo Abayomi Street, Victoria Island, Lagos State, Nigeria.

email: ask4koleayo@gmail.com

\section{Abstract:}

Aim: This study examined pesticide residue levels in three fresh fruit varieties commonly consumed in Lagos state, Nigeria.

Study Design: The fruits (apple, watermelon and sweet orange) were collected from various sale points of fruits in three local government areas; Eti-osa (Ajah), Lagos mainland (Oyingbo) and Ifako-ijaiye (Ifako-ljaiye).

Methodology: Pesticide residue levels were determined using gas chromatography/mass spectrometry (GC-MS). Data obtained from GCMS were statistically analysed using graph pad prism 6.0 software and compared with WHO/FAO limits.

Results: No significant difference $(P>0.05)$ in each fruit was obtained per sampling locations. Fruits contained pesticides below WHO/FAO limit except for watermelon that had mean pesticide residue concentration for atrazine $(0.088-0.133 \mathrm{mg} / \mathrm{kg})$, clothianidin $(0.00-0.029 \mathrm{mg} / \mathrm{kg})$, omethoate $(0.094-0.205 \mathrm{mg} / \mathrm{kg})$ and oxamyloxime $(0.088-0.125 \mathrm{mg} / \mathrm{kg})$ above WHO/FAO MRLs of $0.02,0.02,0.01$ and $0.03 \mathrm{mg} / \mathrm{kg}$ for atrazine, clothianidin, omethoate and oxamyloxime respectively.

Conclusion: The presence of pesticides in these fruits calls for strict regulation regarding the application of pesticides in farms and preservation chambers. This study recommends further investigation of all agricultural produce to circumvent contamination and other problems associated with pesticide accumulation and toxicity.

Keywords: Monitoring; Fresh Fruits; Pesticide residues; MRLs; Nigeria 


\section{INTRODUCTION}

The prevalence of pest attack and diseases among other causes of global food insecurity remains one of the most exigent concerns in recent times. Though advancements made in science and technology have made it possible for farmers to leverage on the use of some chemicals with the ability to kill, repel or control pest known as pesticides. Indeed, pesticides have contributed to the dramatic increase in crop yields, providing variety of diet, increased profits for farmers and have helped to limit the spread of certain diseases and to lower food prices.

Insects and fungi proliferation in fruit crops is a major concern for farmers, wholesalers and retailers of fresh fruits in Nigeria. In an attempt to prevent the natural propensity of stored fruits spoilage and/or reduce the incidence of insect and fungi pests attack on fresh fruits and vegetables, the use of pesticides are usually relied upon. In spite of the overriding importance of the use of pesticides to increase fruit yield, protect stored fruits and control insect vectors, however its use may be quite controversial in that small amounts of pesticide may remain in the crops or animal food [1]. Hence, these pesticide residues may have toxicological significance because of its ability to bio-accumulate for long period causing toxic effect to living organisms in the food chain [1].

Severe poisoning with pesticides is a global public health problem that accounts for as many as 300000 deaths worldwide every year with majority of deaths occurring due to exposure to organophosphates, organochlorines and aluminium phosphide. There is growing evidence that majority of foods in Nigerian markets are contaminated with pesticides [2] [3] [4]. Infants, children and adults are all vulnerable to the risk of pesticides if such food items contaminated with pesticides are consumed [5]. Myriads of human health hazards (such as acute neurologic toxicity, chronic neurodevelopmental impairment, cancer, reproductive dysfunction, and dysfunction of the immune and endocrine systems etc) have been linked to pesticide exposure [6].

Fresh fruits (e.g. watermelon, sweet orange and apple etc.) are supplementary sources of carbohydrates, fibre, lipids, vitamins, minerals and other important nutrients that are vital requisites for growth and continuity of vigour [7]. High intake of fruits have been encouraged not only to prevent consequences due to vitamin deficiency but also to boost immunity functions against the risk of developing major diseases such as cancer [8], cardiovascular diseases and obesity. However, there is dearth of information on the impact of pesticides on nutritional value of food crops. Earlier study posits that application of pesticides may reduce the nutritive value of harvested plants [9] but no substantial information have been made thus far. Going by available information available from researches from other parts of the world on the presence of pesticides in food [10] [11] [12] [13] and their toxic potentials, it is important to have information on the pesticide residues and associated risk of consuming fruits with pesticides in Lagos, Nigeria. Fresh fruits could also be a potential source of harmful and toxic substances. Hence, safety of these fruits is vital for the survival of human and frugivores in the food chain and must be encouraged by consumers, food producers, academics and government agencies [7].

To this end, this study attempts to provide monitoring information on the levels of pesticides' residues in fruits commonly consumed in Lagos State, Nigeria because there is paucity of information on the pesticide residue in the fresh fruits consumed in Lagos, being the commercial city of Nigeria.

\section{MATERIAL AND METHODS}

\section{Sample collection}

Three (3) fresh fruit varieties namely apple (Malus domestica), watermelon (Citrullus lanatus) and sweet orange (Citrus sinensis) were collected from massively patronised sale points of fruits in 3 Local government areas (LGAs) in Lagos state, Nigeria (see figure 1). The fruits were considered representative of the commonly consumed fruits in Lagos. The sampling locations for these LGAs include Eti-osa (Ajah), Lagos mainland (Oyingbo) and Ifako-ijaiye (Ifako-ijaiye). Lagos is situated at $6^{\circ} 45^{\prime}$ North latitude, $3^{\circ} 4^{\prime}$ East longitude and 35 meters elevation above the sea level. Lagos is mega city in Nigeria, having about 9,000,000 inhabitants [7]. A total of 81 fruits were sampled in 9 sampling points in the 3 LGAs which imply that 3 apples, 3 water-melons and 3 sweet oranges were sampled per location. Samples were put in polythene bags, labelled properly and taken to the laboratory for appropriate analysis. Fruit samples were thoroughly shredded and homogenized.

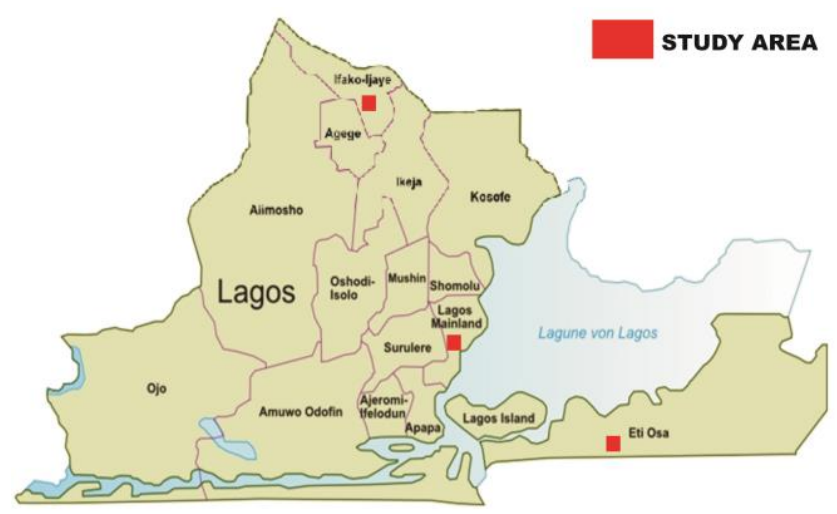

Figure 1: Map of Lagos showing the geographical locations of the study area

\section{Sample preparation}

Sample preparation and extraction followed the procedures described by Ferrer et al. (2005)

[14]. About $(10 \mathrm{~g})$ of each fruit was weighed into a porcelain mortar, and ground with $50 \mathrm{~g}$ of anhydrous 
sodium sulphate. The powdered sample was extracted in ethyl acetate. The extract was rotary evaporated at $40^{\circ} \mathrm{C}$, and the residue re-dissolved in hexane. Sample clean-up was done following the procedure described by Hsu et al. (1991) [15].

\section{Determination of pesticide residue levels}

The analysis of fruit samples for pesticide compounds was performed as was described by Botwe et. al (2011) [10] on a GC-MS (Agilent 6890 Series GC System) coupled with an Agilent 5973N mass selective detectorelectron impact ionization. The capillary column was HP-5MS (length $30 \mathrm{~m}$; I.D $0.25 \mathrm{~mm}$ and film thickness $0.25 \mu \mathrm{m}$ ) and packed with $5 \%$ phenyl methyl siloxane. The GC-MS was operated in the selected ionmonitoring mode at the following conditions [3]: injection port $250^{\circ} \mathrm{C}$ (splitless, pressure 22.62 psi; purge flow 50 $\mathrm{ml} / \mathrm{min}$; purge time $2.0 \mathrm{~min}$; total flow $55.4 \mathrm{ml} / \mathrm{min}$ ). Column oven: initial $70^{\circ} \mathrm{C}$ held $2 \mathrm{~min}$, programming rate $25^{\circ} \mathrm{C} / \mathrm{min}$ (70 to $\left.150^{\circ} \mathrm{C}\right) ; 10^{\circ} \mathrm{C} / \mathrm{min}\left(150\right.$ to $\left.200^{\circ} \mathrm{C}\right)$; $8^{\circ} \mathrm{C} / \mathrm{min}\left(200\right.$ to $280^{\circ} \mathrm{C}$ ) and held $10 \mathrm{~min}$ at $280^{\circ} \mathrm{C}$. The carrier gas was nitrogen at 15 psi; detector make-up, 30 $\mathrm{ml} / \mathrm{min}$. The injection volume was $1 \mu \mathrm{l}$ (Agilent 7683 Series injector).

\section{Calculation for pesticide residue in sample}

The peak area of the sample was compared to that of the standard in relative to the concentration of the standard to get the concentration of the sample.

$$
\begin{aligned}
& \begin{array}{l}
\text { Concentration of } \\
\text { sample }
\end{array}=\frac{\text { Peak area of sample }}{\text { Peak area of standard }} \\
& \text { of standard }
\end{aligned}
$$

Given that, Peak area of sample $=$ Total peak area - solvent peak area

\section{Statistical Analyses}

Descriptive statistics (mean and standard error) was used to analyze results obtained for different pesticides in each fruits. Mean differences in fruits for different study locations were determined using a two-way ANOVA and Turkey's multiple comparison test $(p<0.05$, $p<0.01$ and $p<0.001$ confidence intervals). All analyses were performed using Graphpad prism 6 software.

\section{RESULT AND DISCUSSIONS}

The results presented in table 1, 2 and 3 show that different pesticides were detected in fruits sampled irrespective of their location. However, two-way analysis of variance (ANOVA) and Turkey's multiple comparison test show that pesticides detected in each fruit per location were statistically similar $(P>0.05)$. All fruits were found contaminated with pesticides irrespective of location sourced from, but residues detected in apples and sweet oranges were found below WHO MRLs. The most frequently detected pesticide residues in watermelons were atrazine, clothianidin, omethoate and oxamyloxime. The mean residue concentration for atrazine (0.088-0.133 $\mathrm{mg} / \mathrm{kg}$ ), clothianidin (0.00 - $0.029 \mathrm{mg} / \mathrm{kg})$, omethoate $(0.094-0.205 \mathrm{mg} / \mathrm{kg})$ and oxamyloxime $(0.088-0.125$ $\mathrm{mg} / \mathrm{kg}$ ) as obtained in watermelons in this study were found to be above WHO/FAO MRLs of $0.02,0.02$,
0.01 and $0.03 \mathrm{mg} / \mathrm{kg}$ for atrazine, clothianidin, omethoate and oxamyloxime respectively (Table 3). More pesticides were detected in apples than sweet oranges and watermelons, even though none of these residues in apples were above WHO MRLs. If fresh fruits in cities are handled as appropriate, especially proper washing, then the health hazards associated with pesticide residue levels would greatly reduce in these locations.

Since various pesticides are used globally to circumvent pest infestation to fruits and vegetables, therefore, pesticide monitoring is critical to ensuring that pesticides in fruits and vegetables do not exceed maximum residue levels (MRLs) allowed by World Health Organization (WHO) or relevant food safety authorities in our country. If intended MRL of pesticides exceeds, this then causes various diseases [17]. For this study, pesticide residue levels in common fruits consumed in Lagos State, Nigeria (apple, sweet orange and water melon) were compared to WHO MRLs. MRLs are defined as the highest concentrations of pesticide residues (expressed in milligrams of a substance per kilogram of commodity) likely to occur in or on food commodities after the use of plant protection products according to Good Agricultural Practice (GAP) [18]. All fruits sampled in this study were found contaminated with pesticides (in varying amounts) irrespective of the different locations they were sourced from. The application of different pesticides may result in the contamination of soil, water and food as it does not only adhere to crops and fruits, but is also absorbed into the fruits, and can transfer to human when they consumed [17]. Thus, translocation of pesticides applied to the plant may even happen before the edible part of the plant is formed. More so, the basic processes acting on pesticide residues in the field can continue to operate after crops are harvested. These processes include: volatilization, hydrolysis, penetration, metabolism, enzymatic transformation, oxidation and photodegradation, which generally ceases or is greatly reduced once a crop is removed from the field situation [19].

The detection of the different pesticides in the tissues of the fruits show that the fruits were earlier exposed to pesticides at one stage of their production or the other. But since most fruits in cities are largely grown and supplied by people in neighbouring towns, pesticide residues detected here may also be influenced during storage, handling and processing that occur between harvesting and consumption. Residues detected in fruits in this present study were quite different from the residues detected in similar fruits in recent studies conducted in Ghana [20]. This could possibly be because of the different pesticides in use for different countries. This has also reflected in the almost similar trend in their concentrations across all sampling locations of the present study.

The application of pesticides to crops requires standard safety and quality measures as demonstrated in a new approach termed "Pesticide 
dose adjustment for tree-fruit spraying" [21]. Farmers and consumers face immense risks of exposure due to the use of toxic chemicals that are banned or restricted in other developed countries [22] [23] and developing countries with poor quality control system are most likely to be at the receiving end [24]. The application of pesticides to crops is mostly target-specific that is, it depends on the kind of pests. Different classes of pesticides were observed for all fruits in this study. This may be that majority of rural farmers and fruit wholesalers are unaware of type, recommended dose, time and application method of the pesticides. Apple is well known for its beautiful appearance, crispy flesh, pleasant flavour and sweet taste which attract consumers and fetch high price [25]. A number of pesticides are usually applied to apple in order to curb excessive damage due to their propensity for spoilage in certain environmental conditions. In apples, fungicides and insecticides were the two classes of pesticides frequently observed per study location. Carbendazim, diphenylamine, fludioxonil, pyrimethanil, pyroclostrobin, and thiabendazole as detected in apples belong to the class of fungicide, while acetamiprid, carbaryl, chlorantranipole, endosulfan, methoxyfenozide, phosmet and thiacloprid are insecticides. Most of these fungicides detected in apples were pre- or post-harvest scald inhibitors that may help to extend the shelf lives of apples. While, most residues of insecticides observed in apples were active ingredients of pesticides used in the control of a variety of sucking and chewing insects that may likely attack apples both on fields and storage. This reason may account for the large number of pesticide residues detected in apples compared with other fruits in this study. Based on the results presented in Table 1, mean residue levels for each pesticide detected were found below their WHO MRLs and thus, gives an indication that apples for all sampling locations in this study were safe for public consumption. The results obtained from this study has also shown that these pesticides in apples are obviously heavily utilized in the region where they were grown, and this could probably be due to their easy availability and dependability. This has also reflected in almost similar trend in their concentrations across all sampling locations of this present study.

Sweet oranges are fruits of high economic value. In Nigeria, the use of pesticide on fruit tree crops such as sweet orange is not uncommon. In sweet oranges sampled in this study, fungicides and insecticides were the two classes of pesticides frequently observed per study locations. The fungicides found present in sweet oranges include azoxystrobin, dicloran, fludioxonil, imazalil and thiabendazole, while insecticides found present include aldicarbsulfoxide, carbaryl, chloropyrifos, formethanate, imidacloprid and methomyl. The mean residue levels for each pesticide detected were below their WHO MRLs and thus, gives an indication that sweet oranges for all sampling locations in this study were safe for public consumption. Though the residues of various pesticides obtained both apples and sweet oranges were below their respective WHO MRLs (see Table 1 and 2 ) but then this study further depicts that some of these residues that are persistent in nature could otherwise be bio-accumulated and biomagnified in the living tissues of consumers if fruits are continuously or daily ingested and hence, may endanger the lives of consumers.

Watermelon is one of the most common staple fruits in the city and peripherals of Lagos State. It is mostly consumed on a daily basis as compared to other fresh fruits due to increased public awareness of its nutritional benefits, particularly its high moisture content and sweet taste which helps to quench thirst and relieve hunger. However, this study identified three classes of pesticides in watermelons namely; herbicide, fungicide and insecticide. The insecticides detected present were acephate, clothianidin, dimethoate, endosulfan sulphate, imidacloprid, methamidophos, omethoate, oxamyl-oxime while fungicides were quinoxyfen and tebuconazole and lastly, atrazine was the only class of herbicide detected in watermelons.

To ensure that watermelon is available to meet the overwhelming demands of the consumers, farmers and merchants used these pesticides (except for atrazine) for post harvest purposes to store and preserve watermelons. Hence, the reason for high MRLs of atrazine, clothianidin, omethoate and oxamyloxime detected in watermelons in the 3 LGAs covered in this present study. This also corroborates the report of Dinham (1993) that the short interval between harvests to market and the likelihood of no testing for pesticide residues in developing countries contributed to frighteningly high residual levels in urban markets [26]. High concentrations of aldrin and dieldrin have also been reported in watermelons in Yobe State, Nigeria [27]. The presence of atrazine, clothianidin, omethoate and oxamyloxime in watermelons at high concentrations above WHO MRLs is alarming and portends grave dangers to health of humans and livestock that feeds on them. This calls for caution in the consumption of watermelons in order to avoid the acute toxicity of these pesticides. Atrazine is a widely used herbicide that could be applied before and after planting to control broadleaf and grassy weeds [28]. Thus, it has been reported that atrazine may cause adverse effects on reproduction, nerves and immune systems in fishes [29]. Earlier studies on humans have reported an increase in birth defects, the leading cause of infant mortality, among infants conceived during periods of peak atrazine use on farms [30] [31]. Clothianidin is an insecticide used mostly in seed treatments on some crops [32]. There is paucity of information on the toxic effect of clothianidin on humans, but recent findings posit that use of clothianidin as seed treatments on some crops pose great risks to small birds, and ingestion of even a few treated seeds could cause mortality or reproductive impairment to sensitive bird species [32]. Omethoate is a known organophosphate insecticide. Human health effects from dimethoate or 
omethoate at low environmental doses are unknown. But, dimethoate has been classified a possible human carcinogen [33]. Oxamyl is an insecticide (carbarmate family) used on field crops, vegetables, fruits, and ornamental plants to kill and control a broad spectrum of insects [34]. Its toxicity in humans is unknown, but it has been reported to be toxic to fish, birds, and other wildlife [35].

Table 1: Pesticide residue levels in apples for different locations

\begin{tabular}{|c|c|c|c|c|}
\hline Pesticides & $\begin{array}{l}\text { MR } \\
\text { Ls } \\
\end{array}$ & Ajah & $\begin{array}{l}\text { Oyingb } \\
\text { o }\end{array}$ & $\begin{array}{l}\text { Ifako- } \\
\text { ljaiye }\end{array}$ \\
\hline & 0.8 & $0.046 \pm 0$. & $0.034 \pm 0$. & \\
\hline \multirow[t]{2}{*}{ Acetamiprid } & 0 & 000 & 000 & ND \\
\hline & 15. & $0.111 \pm 0$. & $0.087 \pm 0$ & $0.072 \pm 0$ \\
\hline Carbaryl & 0 & 000 & 000 & 000 \\
\hline Carbendazi & 3.0 & $0.077 \pm$ & $0.053 \pm 0$ & $0.037 \pm 0$ \\
\hline $\mathrm{m}$ & 0 & 0.000 & 000 & 000 \\
\hline Chlorantran & 0.4 & $0.245 \pm$ & $0.208 \pm 0$. & $0.185 \pm 0$. \\
\hline ilipol & 0 & 0.010 & 000 & 000 \\
\hline Diphenylam & 10. & $0.056 \pm$ & $0.084 \pm 0$. & \\
\hline \multirow[t]{2}{*}{ ine } & 0 & 0.000 & 000 & ND \\
\hline & & $0.072 \pm 0$ & $0.049 \pm 0$. & $0.049 \pm 0$ \\
\hline \multirow[t]{2}{*}{ Endosulfan } & 0.5 & 000 & 000 & 000 \\
\hline & 5.0 & $0.034 \pm 0$. & $0.034 \pm 0$. & \\
\hline Fludioxonil & 0 & 001 & 000 & ND \\
\hline Methoxyfen & 2.0 & $0.133 \pm 0$ & $0.116 \pm 0$. & $0.101 \pm 0$. \\
\hline \multirow{2}{*}{ ozide } & 0 & 000 & 000 & 000 \\
\hline & 10. & $0.051 \pm 0$ & $0.038 \pm 0$. & $0.029 \pm 0$ \\
\hline Phosmet & 0 & 000 & 000 & 000 \\
\hline Pyrimethani & 15. & $0.106 \pm 0$. & $0.079 \pm 0$ & $0.069 \pm 0$ \\
\hline I & 0 & 000 & 000 & 000 \\
\hline Pyroclostro & 0.5 & $0.163 \pm 0$. & $0.139 \pm 0$. & $0.089 \pm 0$ \\
\hline bin & 0 & 000 & 000 & 000 \\
\hline Thiabendaz & 3.0 & $0.064 \pm 0$. & $0.058 \pm 0$. & $0.038 \pm 0$ \\
\hline \multirow[t]{2}{*}{ ole } & 0 & 000 & 000 & 001 \\
\hline & 0.7 & $0.160 \pm 0$. & $0.147 \pm 0$. & $0.115 \pm 0$. \\
\hline Thiacloprid & 0 & 001 & 000 & 000 \\
\hline
\end{tabular}

MRLS-

Values for pesticide residues were expressed as mean average of triplicate determinations; ND = Not Detected; WHO MRLs [16]

Table 2: Pesticide residue levels in sweet orange for different locations

\begin{tabular}{lllll}
\hline Pesticide & $\begin{array}{l}\text { MR } \\
\text { Ls }\end{array}$ & Ajah & $\begin{array}{l}\text { Oyingb } \\
\text { o }\end{array}$ & $\begin{array}{l}\text { Ifako- } \\
\text { ljaiye }\end{array}$ \\
\hline Aldicarbsulf & 0.2 & $0.077 \pm 0$. & $0.077 \pm 0$. & $0.064 \pm 0$. \\
oxide & 0 & 000 & 001 & 000 \\
Azoxystrobi & 15. & $0.136 \pm 0$. & $0.136 \pm 0$. & $0.109 \pm 0$. \\
$\mathrm{n}$ & 0 & 000 & 000 & 000 \\
& 15. & $0.111 \pm 0$. & $0.083 \pm 0$. & $0.083 \pm 0$. \\
Carbaryl & 0 & 001 & 000 & 000 \\
Chlorpyrifo & 1.0 & $0.096 \pm 0$. & $0.096 \pm 0$. & $0.073 \pm 0$. \\
s & 0 & 001 & 000 & 001
\end{tabular}

\begin{tabular}{lllll} 
& 10. & $0.107 \pm 0$. & $0.107 \pm 0$. & $0.064 \pm 0$. \\
Dicloran & 0 & 000 & 000 & 000 \\
& 5.0 & $0.095 \pm 0$. & $0.095 \pm 0$. & $0.054 \pm 0$. \\
Fludioxonil & 0 & 000 & 000 & 000 \\
Formethan & & $0.205 \pm 0$. & $0.205 \pm 0$. & $0.169 \pm 0$. \\
ate & 0.5 & 001 & 000 & 001 \\
& 5.0 & $0.268 \pm 0$. & $0.223 \pm 0$. & $0.189 \pm 0$. \\
Imazalil & 0 & 001 & 001 & 003 \\
Imidaclopri & 1.0 & $0.193 \pm 0$. & $0.149 \pm 0$. & $0.135 \pm 0$. \\
d & 0 & 000 & 001 & 001 \\
& 1.0 & $0.066 \pm 0$. & $0.066 \pm 0$. & $0.066 \pm 0$. \\
Methomyl & 0 & 000 & 000 & 000 \\
Thiabendaz & 3.0 & $0.203 \pm 0$. & $0.163 \pm 0$. & $0.151 \pm 0$. \\
ole & 0 & 001 & 000 & 001 \\
\hline
\end{tabular}

Values for pesticide residues were expressed as mean average of triplicate determinations; ND = Not Detected; WHO MRLs [16]

Table 3: Pesticide residue levels $(\mathrm{mg} / \mathrm{kg})$ in watermelons for different locations

\begin{tabular}{lllll}
\hline Pesticide & $\begin{array}{l}\text { MR } \\
\text { Ls }\end{array}$ & Ajah & Oyingbo & $\begin{array}{l}\text { Ifako- } \\
\text { ljaiye }\end{array}$ \\
\hline Acephate & 5.0 & $0.049 \pm 0$. & $0.031 \pm 0$. & $0.031 \pm 0$. \\
& 0.0 & $0.133 \pm$ & 000 & 000 \\
Atrazine & 2 & $0.000^{*}$ & $000^{*} \pm 0$. & $0.088 \pm 0$. \\
Clothianidi & 0.0 & $0.029 \pm 0$. & $0.029 \pm 0$. & \\
$\mathrm{n}$ & 2 & $000^{*}$ & $000^{*}$ & $\mathrm{ND}$ \\
Dimethoat & & $0.254 \pm 0$. & $0.218 \pm 0$. & $0.193 \pm 0$. \\
$\mathrm{e}$ & 2.0 & 000 & 000 & 000 \\
Endosulfa & & $0.239 \pm 0$. & $0.196 \pm 0$. & $0.171 \pm 0$. \\
n sulf & 0.5 & 000 & 001 & 001 \\
Imidaclopri & 1.0 & $0.111 \pm 0$. & $0.111 \pm 0$. & $0.089 \pm 0$. \\
d & 0 & 000 & 000 & 000 \\
Methamid & & $0.330 \pm 0$. & $0.282 \pm 0$. & $0.266 \pm 0$. \\
ophos & 0.5 & 099 & 000 & 000 \\
Omethoat & 0.0 & $0.205 \pm 0$. & $0.173 \pm 0$. & $0.094 \pm 0$. \\
e & 1 & $000^{*}$ & $000^{*}$ & $001^{*}$ \\
Oxamyloxi & 0.0 & $0.125 \pm 0$. & $0.104 \pm 0$. & $0.088 \pm 0$. \\
me & 3 & $000^{*}$ & $001^{*}$ & $000^{*}$ \\
Quinoxyfe & 0.4 & $0.171 \pm 0$. & $0.171 \pm 0$. & $0.135 \pm 0$. \\
$\mathrm{n}$ & 0 & 000 & 000 & 000 \\
Tebucona & 1.0 & $0.159 \pm 0$. & $0.159 \pm 0$. & $0.142 \pm 0$. \\
zole & 0 & 001 & 000 & 001 \\
\hline
\end{tabular}

Values for pesticide residues were expressed as mean average of triplicate determinations; ND $=$ Not Detected; * exceeded MRL; WHO MRLs [16]

\section{CONCLUSION AND RECOMMENDATIONS}

The presence of pesticide residues in all fruits used for this study calls for stringent measures in the regulation of the use of pesticides for crop protection, yield improvement and storage. Atrazine, clothianidin, omethoate and oxamyloxime among several pesticides found in watermelons were above their respective WHO/FAO MRLs. This is alarming and 
portends grave dangers to health of humans and livestock.

Based on the observations in this study, the followings were recommended:

i. Further research should be carried out to substantiate if the presence of pesticides will affect the nutritional value of fresh fruits in Nigeria. More evidence is needed.

ii. Further research should also be carried out to determine the hazard quotient (HQ) and estimated daily intake (EDI) with special regards to dietary exposure to pesticides for a large class of fruits and vegetables in order to ensure a healthy lifestyle and well-being in cities.

iii. The entire public should be sensitised on the dangers of pesticide contamination in food intake and the need to inculcate good habits of washing fruits thoroughly before consumption.

iv. Improving sanitary conditions of city food markets will help to curb the menace of fresh fruits- pesticide contamination.

v. It is critically essential to train agricultural extension workers, rural and urban farmers on the judicious use of pesticides in pre- and postharvest production of fruits and on recent mitigation approaches such as "pesticide dose adjustment for tree-fruit spraying".

vi. Government and stakeholders should also encourage the use of biodegradable pesticides and grow genetically modified-pest resistant fruit crops.

\section{ACKNOWLEDGEMENTS}

Authors extend gratitude to Joe Orizu for his technical support during laboratory analysis, to Steven Aderemi for assistance on statistical analysis, and lastly to our anonymous reviewers for their editorial insights.

\section{COMPETING INTERESTS}

Authors have declared that no competing interests exist.

\section{AUTHORS' CONTRIBUTIONS}

Koleayo Omoyajowo and Kelechi Njoku designed the study; Kelechi Njoku supervised and managed the analysis and literature review. Koleayo Omoyajowo wrote the first draft of the manuscript. Sunday Amiolemen, John Ogidan, Olapeju Adenekan, Kayode Olaniyan, Julie Akande and Ifeoluwa Idowu wrote the protocol, managed the literature searches and performed the statistical analysis. All authors read and approved the final manuscript.

\section{REFERENCES}

[1] Centre for Food Safety (CFS), 2007. Proposed Regulatory Framework for Pesticide residues in
Food in Hong Kong. Food and Environmental Hygiene Department, Hong Kong 34p.

[2] Olufade, Y.A., Sosan, M.B., Oyekunle, J.A.O. 2014. Levels of Organochlorine Insecticide Residues in Cowpea Grains and Dried Yam Chips from Markets in Ile-Ife, Southwestern Nigeria: A Preliminary Survey Ife Journal of Science vol. 16(2): 161-170.

[3] Njoku, K. L., Ezeh, C. V., Obidi, F. O. and Akinola, M. O. 2017. Assessment of Pesticide Residue Levels in Vegetables sold in some Markets in Lagos State, Nigeria. Nig. J. Biotech. 32: $53-60$

[4] Gwary, O.M., Hati, S.S., Dimari G.A and Ogugbuaja, V. O. 2012. Pesticide Residues in Bean Samples from Northeastern Nigeria. ARPN Journal of Science and Technology 2(2) 79-84.

[5] Centre for Ecogenetics and Environmental Health (2013) Fast Facts about Health Risks of Pesticides in Food. Retrived from https://depts.washington.edu/ceeh/downloads/ FF Pesticides.pdf on 23rd April 2017.

[6] Andersson H., Tago D., and Treich N., 2014. Pesticides and health: A review of evidence on health effects,valuation of risks, and benefitcost analysis. Advances in Health Economics and Health Services Research. 8: 1-61.

[7] Omoyajowo, K.O, Njoku, K.L., Babalola, O.O., Adenekan, O.A. (2017). Nutritional composition and heavy metal content of selected fruits in Nigeria. Journal of Agriculture and Environment for International Development 111 (1): 123-139.

[8] Wattenberg, L.W. (1992) Inhibition of carcinogenesis by minor dietary constituents. Cancer Research, 52, 2085- 2091.

[9] Berger S, Pardo B, and SkorkowskaZieleniewska J. 1980. Nutritional implications of pesticides in foods. Bib/ Nutr Dieta. 29:1-10

[10] Botwe, B. O. Ntow, W. J., Kelderman, P. , Drechsel, P., Carboo, D., Nartey, V. K. and Gijzen, H. J. (2011) Pesticide Residues Contamination of Vegetables and Their Public Health Implications in Ghana. J. Environ. Issues Agric. Dev. Countries 3 (2): 1-18.

[11] Claeys W.L, Jean-Francois S., Bragard C, Maghuin-Rogister G, Luc P, and Schiffers B., 2011. Exposure of several Belgian consumer groups to pesticide residues through fresh fruit and vegetable consumption. Food Control 22: 508-516.

[12] Petersen, A., Hamborg, B. J., Andersen, J. H., Poulsen, M. E., Christensen, T. and Nielsen, E. (2013) Pesticide Residues Results from the period 2004-2011. Prepared by National Food Institute, Technical University of Denmark, 138pp. Retrieved from www.food.dtu.dk on 12th December 2016.

[13] Qin, G., Zou, K., Li, Y., Chen, Y., He, F., and Ding, G. (2016). Pesticide residue determination in vegetables from western China applying gas chromatography with 
spectrometry. Biomed. Chromatography, 30 (9): 1430 - 1440.

[14] Ferrer, I., García-Reyes, J. F., Mezcua, M., Thurman, E.M. and Fernández-Alba, A.R. (2005). Multi-residue pesticide analysis in fruits and vegetables by liquid chromatography-time of-flight mass spectrometry.

Chromatography A 1082: 81-90

[15] Hsu R.C., Biggs I. and Saini N. K. (1991). SolidPhase Extraction Cleanup of Halogenated Organic Pesticides. J. Agric. Fd. Chem. 39, 1658-1666.

[16] Joint FAO/WHO Codex Alimentarius (2016). Codex Pesticides Residues in Food Online Database Retrieved from www.fao.org/faowho-codexalimentarius on 09/11/2016.

[17] Khan, M.S, Shah, M.M, Mahmood Q., Hassan A., and Akbar K., 2011. Assessment of pesticide residues on selected fruit and vegetables of Pakistan. Journal of Chemical Society Pakistan. 33(6):816-821.

[18] WHO (2016). Pesticide Residues in Food. Retrieved from http://www.who.int/feature/9a/87/en. on 28th September, 2016.

[19] Holland P. T., Hamilton D., Ohlin B. and Skidmore M. W. 1994. Effects of Storage and Processing on Pesticide Residues in Plant Products, IUPAC Reports on Pesticides (31) Pure and Appl. Chem. 66(2): 335- 356.

[20] Bempah C.K., Buah-Kwofie A., Denutsui D., Asomaning J. and Tutu A.O., 2011. Monitoring of pesticide residues in fruits and vegetables and related health risk assessment in Kumasi metropolis, Ghana. Research Journal of Environmental and Earth Sciences 3(6): 761771.

[21] AHDB. 2017. Pesticide dose adjustment for tree-fruit spraying Retrieved from http://pjwrc.co.uk/DoseAdjustment.htm) on July 23, 2017.

[22] Nasr, I. N., Sallam, A. A. A. and Abd El-Khair, A. A. 2007. Monitoring of certain pesticide residues and some heavy metals in fresh cow's milk at gharbia governorate, Egypt.J. Applied Sci., 7, 3038-3044.

[23] Adhikari, S. 2010. Bioremediation of malathion from environment for pollution control. Res. J. Environ. Toxicol. 4, 147-150.

[24] Osibanjo O., Biney C., Calamari N., Kaba N., Mbome I.L., Naeve H., Ochumba P.B.O. and Saad M.A., 1994. Chlorinated Hydrocarbon substances, Flood and Agriculture Organisation Fish Report 502:2.

[25] Abdualrahman M. A., 2015. Comparative study between local and imported apple (Malus domestica) fruits and their uses in juice production. Science International 3 (2): 69-72.

[26] Dinham, B. 1993. Growing vegetables in developing countries for local urban populations and export markets: Problems confronting small-scale producers. Pesticide Management and Science, 59, 575-582.
[27] Akan, J.C. Mahmud, M.M., Waziri, M., Mohammed Z. 2015., Residues of Organochlorine Pesticides in Watermelon (Citrulus lanatus) and Soil Samples from Gashua, Bade Local Government Area Yobe State, Nigeria, Advances in Analytical Chemistry, 5 (3): 61-68.

[28] United States Environmental Protection Agency, 2017. Atrazine - Background and Updates. Retrieved https://www.epa.gov/ingredients-usedpesticide-products/ on July 23, 2017.

[29] Wang, X., Li, J., Xing, H. and Xu, S. 2011. Review of Toxicology of Atrazine and chlorpyrifos on fish. Journal of Northeast Agricultural University 18 (4): 88 -92.

[30] Mattix, K.D., Winchester, P.D., and Scherer, L.R. 2007. Incidence of abdominal wall defects is related to surface water atrazine and nitrate levels. J. Pediatr. Surg., 42(6):947-949.

[31] Winchester, P.D., Huskins, J. and Ying, J. 2009. Agrichemicals in surface water and birth defects in the United States. Act Paediatrica. (98): 664-669.

[32] Gibbons D, Morrissey C., and Mineau, P. 2015. A review of the direct and indirect effects of neonicotinoids and fipronil on vertebrate wildlife. Environ Sci Pollut Res 22:103-118.

[33] U.S. Environmental Protection Agency. 1995. Dimethoate; pesticide tolerance. Proposed rule. In: Federal Register 60 (128): 3494534947.

[34] Meister, R.T. (ed.). 1991. Farm Chemicals Handbook '91. Meister Publishing Company, Willoughby, $\mathrm{OH}$.

[35] Extension Toxicology Network. 1993. Pesticide information profile of Oxamyl. Retrieved from http://pmep.cce.cornell.edu/profiles/extoxnet/m etiram-propoxur/oxamyl-ext.html on July 13, 2017. 